\section{Prática comunicativa no portal do MEC: Um estudo do plano da expressão}

Communicative practice in the MEC portal: A study of the expression plane

Flávia Furlan GRANATO (UNESP)

flaviafurlang@yahoo.com.br

Naiá Sadi CÂMARA (UNAERP)

naiasadi@gmail.com

Recebido em: 30 de jan. de 2018. Aceito em: 17 de jun. de 2018.

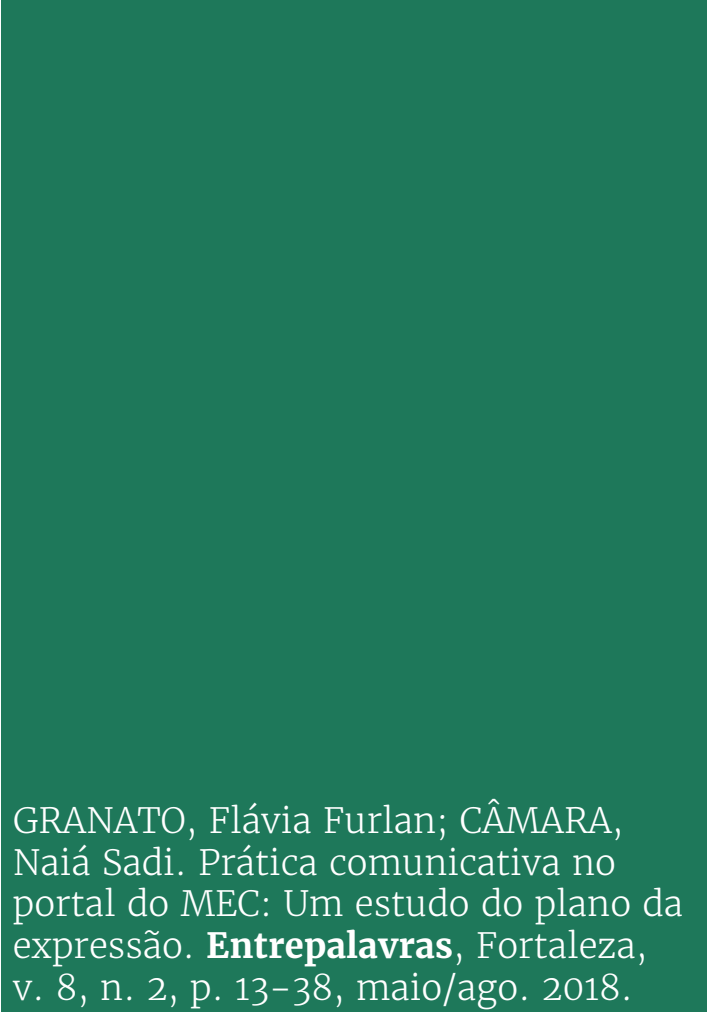

Resumo: O Ministério da Educação (MEC) é responsável por legislar, criar, gerenciar e cobrar leis que se aplicam à educação do nosso país, exercendo, dessa forma, o papel de destinador social. A fim de aderir às novas formas de interação que as práticas comunicativas contemporâneas exigem, o MEC passou a se comunicar com a sociedade não apenas por meio dos textos impressos (documentos, manuais etc.), mas também por meio de práticas comunicativas digitais espalhadas pelos diversos espaços da Internet. Considerando que essas práticas digitais ocorrem em um universo hipersemiotizado, multimodal, híbrido e aberto, perguntamo-nos, neste trabalho, como se configurariam as práticas comunicativas do Ministério da Educação nesse novo ambiente, especificamente em seu Portal na Internet. Com o objetivo de responder a essas questões, propusemonos analisar o modo como o MEC organiza a prática da visita em seu site e como harmoniza o encadeamento das cenas enunciativas partindo de um estudo do suporte planar através das categorias cromáticas, topológicas e eidéticas desse espaço, compreendendo, dessa forma, as categorias do plano de expressão e, por conseguinte, as do plano de conteúdo, 
V. $8(2)$

$13-38$

mai/ago 2018

com base no modelo de análise da semiótica greimasiana, especialmente através dos níveis de pertinência de análise de Fontanille (2008) e do modelo de análise do texto sincrético proposto por Teixeira $(2009,2013)$. O estudo da prática comunicativa do MEC em seu portal nos permitiu comprovar as estratégias persuasivas decorrentes do sincretismo empregado na mídia digital e observar a experiência interpretativa do interlocutor que navega pelo espaço.

Palavras chaves: Práticas semióticas. Níveis de pertinência. Enunciação sincrética.

Abstract: The Ministry of Education (MEC) is responsible for legislating, creating, managing and enforcing laws that apply to education in Brazil, assuming, therefore, the role of social addresser. In order to comply with new forms of interaction demanded by contemporary practices, MEC started to communicate with society not only through printed materials (documents, manuals, etc.), but also through digital communicative practices, spread across several spaces of the Internet. Considering that digital communication practices occur in a hypersemiotized, multimodal, hybrid and open universe, we asked ourselves how the Ministry of Education would configure the communication practices in this new environment, especially their Web Portal. In order to answer these questions, we propose to analyze how MEC organizes the practice of a visit to their website, and how it harmonizes the concatenation of enunciative categories, based on a study of planar support through the chromatic, topological and eidetic categories of this space, thus comprising the categories of the expression plane and, therefore, those of the content plane, based on the analysis model of greimasian semiotics, especially through the levels of relevance analysis of Fontanille (2008) and syncretic text analysis model proposed by Teixeira (2009, 2013). The study of the communicative practice of the MEC in its portal allowed us to prove the persuasive strategies resulting from the syncretism employed in the digital media and to observe the interpretative experience of the interlocutor who navigates through space.

Keywords: Semiotic practices. Levels of relevance. Syncretic enunciation.

\section{Introdução}

Este artigo apresenta os resultados finais de nossa pesquisa de mestrado a qual objetivou analisar as práticas comunicativas do MEC realizadas no ambiente digital da Internet, a fim de verificarmos as características que esse enunciador, destinador social das leis e diretrizes nacionais da educação, imprime nesse objeto suporte.

Com o propósito de realizar tal investigação, passamos a observar o seu portal, acessado pelo endereço digital www.mec.org.br, e levantar suas características em relação à ocupação do espaço, aos gêneros escolhidos para comporem a página principal e às linguagens empregadas, de modo a entendermos como o MEC organiza a prática de visita nesse ambiente de interação digital.

Há poucas décadas, o Ministério da Educação comunicava-se, predominantemente, por meio de documentos impressos, através de textos verbais, no formato de leis, normas, projetos que eram publicados em diferentes suportes convencionais para a época, como documentos, 
revistas, livros, jornais, ou seja, em mídias impressas. Porém, no final da década de 1990, a fim de atualizar-se em relação às novas tecnologias, o MEC passou a se utilizar também das mídias digitais para inscrever e circular seus textos.

Se considerarmos que a Internet possibilita uma maior acessibilidade aos seus conteúdos, já que estes podem ficar disponíveis em seus espaços por longos períodos e até permanentemente, podemos pressupor que, ao estabelecer-se com essa nova forma de comunicação, o Ministério tornou-se mais acessível não apenas aos profissionais ligados diretamente à educação, bem como a qualquer cidadão que tenha interesse em suas publicações. Acreditamos também que a possibilidade de utilização de diferentes linguagens e os mais variados gêneros textuais, características típicas das produções da Internet, possam também ter tornado seus textos mais acessíveis, informais e, portanto, mais próximos de seus interlocutores.

O percurso teórico utilizado teve como princípio fundamental os estudos da teoria semiótica francesa com base nos níveis de pertinência do percurso gerativo da expressão de Jacques Fontanille (2008) que, no início dos anos 2000, desenvolveu uma hierarquia dos níveis de pertinência ${ }^{1}$ na produção do sentido. Outros conceitos foram utilizados como, por exemplo, os estudos acerca do sincretismo propostos por Lúcia Teixeira (2009, 2013, 2015) em sua metodologia de análise dos textos verbovisuais, e considerações acerca do gênero numa abordagem semiótica por Fontamille (1999), Portela e Schwartzmann (2012).

\section{Considerações teórico-metodológicas}

Pensar no uso da língua para a construção e a análise de um discurso é, segundo Fiorin (2016, p. 25), colocar "em jogo um enunciador e um enunciatário com seus diversos pontos de vista". Dessa maneira, temos o MEC como enunciador de uma prática comunicativa em seu portal na Internet e seus enunciatários, que irão interpretar as linguagens que lhes serão apresentadas em forma de textos-enunciados.

Consoante o autor (2008), os textos da comunicação são produtos de linguagem e podem ser explorados e analisados pelas teorias linguísticas, como a semiótica:

${ }^{1}$ Composto por seis níveis: signos, textos, objetos, cenas predicativas, estratégias e formas de vida. 
V. 8 (2)

$13-38$

mai/ago 2018

[...] os meios de comunicação podem ser estudados do ponto de vista da significação, uma teoria semiótica deve poder ser empregada no seu estudo, já que a Semiótica se propõe como teoria da significação. O sentido gerado por um filme não é diferente daquele criado por um romance. O que distingue um objeto do outro é apenas a forma de manifestar essa significação, é o plano da expressão. No entanto, as teorias semióticas modernas estão buscando analisar as diferentes manifestações possíveis da significação e, portanto, não são alheias a nenhuma forma de exprimir o sentido. (FIORIN, 2008, p.78)

No âmbito das novas mídias, o estudo semiótico direcionouse ao estudo dos sincretismos a fim de explicar como as linguagens combinam-se e hierarquizam-se, como nos explica Oliveira:

A postulação que fazemos é que o estudo semiótico do sincretismo da expressão faz-se no âmbito do pôr em discurso com uma dada escolha organizadora do plano da expressão, sendo seu lugar teórico os estudos da enunciação global, que permitem dar conta dos processos de escolha e usos do enunciador, caracterizando-o ao mesmo tempo que edificam os seus regimes de interação com o enunciatário, bem como o configurar desses simulacros na imanência do objeto sincrético como simulacros do destinador e do destinatário no contexto situacional de sua ocorrência sócio-histórico-político-cultural. (OLIVEIRA, 2009, p. 84-85)

A enunciação, que é o ato produtor do enunciado, uma instância pressuposta, revelar-se-á através de marcas deixadas no próprio enunciado. Através dessas marcas da enunciação e seus possíveis efeitos de sentido é que buscamos investigar a prática comunicativa do MEC em seu portal.

Em uma enunciação sincrética ${ }^{2}$, segundo Teixeira (2009), as linguagens em uso submetem-se a uma força enunciativa coesiva que dará origem a uma nova linguagem. No caso do site do MEC, temos em questão a força do suporte midiático que, valendo-se de um recurso audiovisual, resulta um sincretismo funcional, pois cada elemento material se sobrepõe suscitando uma estratégia global de comunicação sincrética, bastante propícia para uma interação que seja de fato eficiente. Para uma definição de site a autora explica que

\footnotetext{
${ }^{2}$ Enunciação sincrética, segundo Teixeira (2009, p.47), seria "um objeto que, acionando várias linguagens de manifestação, está submetido, como texto, a uma enunciação única que confere unidade de variação", ou seja, um texto que, para materializa-se, foi constituído de várias linguagens em seu processo de enunciação (construção do enunciado).
} 
[...] são manifestações multimodais submetidas a uma práxis enunciativa que lhes confere unidade de sentido, por meio de parâmetros de organização e design, recorrências temáticas e figurativas e um ritmo próprio. O efeito de unidade é produzido pela resolução sincrética das linguagens em jogo, obtida pela articulação de todos esses elementos. (TEIXEIRA, 2015, p. 37)

Teixeira (2009), diante dessas reflexões sobre o texto sincrético, propõe aos analistas desse discurso um modelo que se inicia com uma descrição exaustiva e minuciosa do corpus e, em seguida, passa pela definição de categorias e pelo exame de procedimentos. Entre os elementos listados pela autora, tomaremos os seguintes como critérios de análise (TEIXEIRA, 2009, p. 61):

1. Figuras e temas disseminados no discurso, por meio dos elementos verbais e visuais; a partir desses aspectos próprios à superfície discursiva;

2. Categorias cromáticas, topológicas e eidéticas do plano da expressão plástica, considerando a ocupação do suporte planar;

3. Mecanismos de articulação entre plano de conteúdo e plano da expressão;

4. Estratégia enunciativa que organiza todos os elementos e estabelece as formas de interação entre enunciador e enunciatário.

Respaldados pela teoria, buscaremos analisar o sentido gerado por esse sincretismo a fim de estabelecer uma interação satisfatória no interior desse enunciado. Esse é um dos olhares para o nosso objeto, que será desvendado à medida que descrevermos seu discurso produzido em um suporte planar, com materialidades próprias a esse domínio.

A produção de um conteúdo para um portal sugere que combinações de linguagens e encadeamentos de cenas predicativas ${ }^{3}$ se construam de acordo com condições espaço-temporais e interações em decorrência dessas situações semióticas. Fontanille $(2005,2008)$ propõe um modelo metodológico de análise para que possamos percorrer essas manifestações sensíveis que darão forma às estruturas narrativas e

\footnotetext{
3 A prática poderá conter um ou vários predicados que serão papéis actanciais desempenhados "pelos próprios textos ou imagens, por seus objetos-suportes, por elementos do ambiente, pelo transeunte, pelo usuário ou pelo observador, tudo o que forma a 'cena' típica de uma prática" (FONTANILLE, 2008, p. 23).
} 
v. $8(2)$

$13-38$

mai/ago 2018

discursivas do plano de conteúdo. Nesse empenho por uma análise um pouco mais eficiente é que buscamos ancoragem nos estudos do autor $(2005 ; 2008)$ sobre o percurso gerativo da expressão sobre o qual faremos uma breve explanação a seguir.

Na interface do nível das figuras-signos ao nível dos textosenunciados, segundo Fontanille (2005), é que nos adentramos na dimensão das unidades mínimas responsáveis pela produção de significados e valores (signos ou figuras) e dos seus conjuntos de significantes (textos-enunciados), sendo esses a apreensão de uma totalidade que podemos reconhecer no primeiro nível, sob a forma material de dados textuais (verbais e não-verbais).

[...] a passagem ao nível de pertinência superior, aquele do texto-enunciado, integra a totalidade ou parte desses elementos sensíveis em uma dimensão plástica; e a análise semiótica dessa dimensão textual pode, então, reconhecer e afetar diretamente as formas de conteúdo, as axiologias, detectar os papéis actanciais. Em síntese, os elementos sensíveis e materiais da imagem só se tornam pertinentes de um ponto de vista semiótico no nível superior, isto é, no momento de sua integração no texto-enunciado. (FONTANILLE, 2005, p. 18)4

Como observa o autor, as figuras-signos são organizadas no texto-enunciado e suas escolhas determinarão a apreensão de uma totalidade sob a forma material de dados textuais (verbais ou nãoverbais).

Já a passagem do nível dos textos-enunciados para o nível dos objetos implica integrar esse texto a um suporte da afixagem. Segundo explicações do próprio Fontanille (2008, p. 25) "o caráter 'material' do suporte não significa que ele deva ser obrigatoriamente tangível. 'Material' deve ser entendido no sentido de Hjelmslev (1975), ou seja, como um substrato sensível das semióticas-objetos".

De acordo com os conceitos fontanillianos (2005, p. 19), o uso do objeto-suporte para inscrição de um texto gera uma eficácia enunciativa e pragmática, pois os objetos são estruturas materiais dotadas de morfologia e funcionalidade a fim de que se veicule segundo as "regras de seu próprio gênero" e que regule "sua interação com os percursos e os usos dos espectadores".

Em nosso trabalho, tratamos a Internet como o suporte de afixagem dos textos-enunciados do MEC, ou seja, esse suporte, como substrato sensível, irá compor os textos de nosso enunciador de acordo

$\overline{4 \text { Grifos do autor. }}$ 
com as suas características. A inscrição dependerá, nesse caso, de regras próprias da mídia digital que irão estabilizar os textos em uma organização temporal e espacial de acordo com a intencionalidade de cada cena predicativa.

$\mathrm{Na}$ interface entre os objetos e as cenas predicativas temos a passagem de um nível inferior para um superior, o nível das situações em geral, o das práticas.

A primeira definição a apresentarmos é o conceito de práticas semióticas segundo o Dicionário de Semiótica (GREIMAS; COURTÉS,2016):

Partindo da definição do sentido como intencionalidade orientada e tendo em conta que as organizações semióticas se constroem no interior dessas duas macrossemióticas que são as línguas naturais e os mundos naturais, denominaremos práticas semióticas os processos semióticos reconhecíveis no interior do mundo natural e definíveis de modo comparável aos discursos que são práticas verbais, isto é, processos semióticos situados no interior das línguas naturais. (GREIMAS; COURTÉS, 2016, p. 380)

Como podemos observar, a prática semiótica é um processo semiótico que, por sua vez, é da ordem do mundo e das línguas naturais. Segundo os autores, ela pode ser qualificada como social e realizada através de comportamentos somáticos, podendo, dessa forma, ser analisada como programas de reconhecimento posterior.

Tratamos, nesta pesquisa, conforme Câmara (2018), a prática comunicativa do MEC como uma prática participativa (GREIMAS; COURTÉS, 2016, p. 82), um processo geral (amplo) que acionará o discurso e o conduzirá a fim de defini-lo enquanto uma "sequência de comportamentos somáticos", e presidida por estruturas contratuais e estruturas polêmicas, que se estabelecem a partir de uma situação semiótica, compreendida como uma configuração heterogênea a qual organiza os diferentes elementos para a produção e interpretação das práticas comunicativas.

Nesse processo semiótico da prática comunicativa do MEC em seu portal, observamos manifestações das enunciações pressupostas, ou seja, no nível das práticas, além do corpo material do objeto, é que nos adentramos na "enunciação em uso", composta por cenas predicativas capazes de produzir sentidos e interpretações.

Teixeira (2013, p. 21) chama atenção para o fato de que na prática de visita online, o que transforma efetivamente a situação semiótica é a relação entre espaço e tempo e não a interação ou regimes 
V. 8 (2)

$13-38$

mai/ago 2018

de presença. Por isso, faz-se importante um estudo dessa prática através da descrição do suporte planar a fim de analisar a trajetória do internauta que se desloca nesse ambiente através de encadeamentos de cenas predicativas. "A situação, portanto, não é o contexto nem o texto, mas a articulação de certas práticas em torno de cenas e estratégias" (TEIXEIRA, 2013, p. 18).

Portanto, a prática de comunicação social do MEC no ambiente digital está, por sua vez, ligada à prática da visita ao portal que é constituída de cenas predicativas pelas quais os usuários percorrerão. Fontanille (2008) esclarece a ligação das práticas com as cenas da seguinte forma:

As práticas recebem uma "forma" (constituintes) de sua confrontação com as outras práticas e, por isso, de um lado, integram os elementos materiais dos níveis inferiores (signos, textos, objetos) para torná-los elementos distintivos e pertinentes e lhes dar "sentido", e de outro lado, recebem um "sentido" de sua própria participação nos níveis superiores (estratégias e formas de vida). A forma das práticas está ligada a sua dimensão predicativa, que designaremos, daqui por diante, como cena predicativa (no sentido em que, na lingüística dos anos 1960, falávamos da predicação verbal como de uma "pequena cena"). Sob esse aspecto, uma prática pode comportar um ou vários processos (um ou vários predicados), atos de enunciação que implicam papéis actanciais desempenhados, entre outros, pelos próprios textos ou imagens, por seus objetos-suportes, por elementos do ambiente, pelo transeunte, pelo usuário ou pelo observador, tudo o que forma a "cena" típica de uma prática. Do mesmo modo ela é composta pelas relações entre esses diferentes papéis, essencialmente relações modais, mas também passionais. Enfim, a prática comporta geralmente uma modificação dos corpos e das figuras, que implica uma sintaxe figurativa. (FONTANILLE, 2008, p. 23)

Como referência para o observador de uma prática, no caso o usuário do site em questão, Fontanille (2008, p. 53) cria em sua teoria dos níveis um regime das práticas, pois todas dependem de uma sequência de resoluções com as quais se organizou em: < falta de sentido - esquematização - regulação - adaptação > . A cada um desses "regimes sintagmáticos" da prática obedecerá, ainda, segundo o autor, modalizações específicas, caracterizadas por um modo de regulação próprio5:

\footnotetext{
5 "Modo de regulação" das práticas retirado de (FONTANILLE, 2008, p. 53).
} 
(1) Práxis (poder): a regulação atua sobre os encadeamentos entre as etapas;

(2) Procedimento (saber): a regulação baseia-se numa programação prévia das fases e de sua sucessão;

(3) Conduta (querer): a esquematização atua por iconização auto-adaptativa e a regulação consiste em uma manifestação figurativa das motivações;

(4) Protocolo (dever): a esquematização é a cristalização dos papéis e das etapas e a regulação, uma projeção imediata desses papéis sobre a imprevisibilidade do percurso;

(5) Ritual (crer): a regulação baseia-se no ritmo e na gestão temporal da sequência.

O último nível de análise dos níveis de pertinência, as formas de vida, está ligado à noção de "estilo de vida" do projeto de Wittgenstein (1975) e foi definido por Fontanille (2014) como:

[...] organizações semióticas ("linguagens") características das identidades culturais, individuais e coletivas, e, como tais, podem ser aproximadas de outros planos semióticos de análise das culturas, como, por exemplo, os objetos, os textos e as práticas. (FONTANILLE, 2014, p. 56)

Numa análise em torno das mídias, segundo Portela (2008a, p. 108), tratar desse nível levaria em conta alguns fenômenos, tais como: "o comportamento e o éthos de seus personagens" e "as formas de vida que presidem a organização dos gêneros e formatos midiáticos consagrados", ou seja, como se dá a organização do suporte planar levando em conta os gêneros e todos os recursos disponíveis por esse modelo de mídia. Segundo esses fenômenos citados acima, optamos por enfatizar o éthos dessa prática no que diz respeito ao enunciador MEC.

Fontanille (2005, p. 31) caracteriza esse último nível como:

A experiência subjacente, o sentimento de uma identidade de comportamento, a percepção de uma regularidade no conjunto de procedimentos de ajustamento estratégico é, pois, a experiência de um éthos, essa experiência, sendo convertida em um dispositivo de expressão pertinente (um estilo exprimindo uma atitude), dá lugar a uma forma de vida que é suscetível de integrar a totalidade dos níveis inferiores para produzir globalmente uma configuração pertinente à análise das culturas. 
v. $8(2)$

$13-38$

mai/ago 2018

Pressupomos, portanto, que a prática da visita ao portal se realizará segundo as escolhas de composição dos enunciados, levando em conta as ações que o enunciador possibilita ao seu enunciatário.

\section{0 ambiente: descrição do suporte planar}

Abaixo, uma descrição do Portal do MEC.

Ao chegarmos à página do Ministério, encontramos a tela, ilustrada em (1).

Figura 1 - Tela inicial do Portal do MEC

\section{minuteriode}
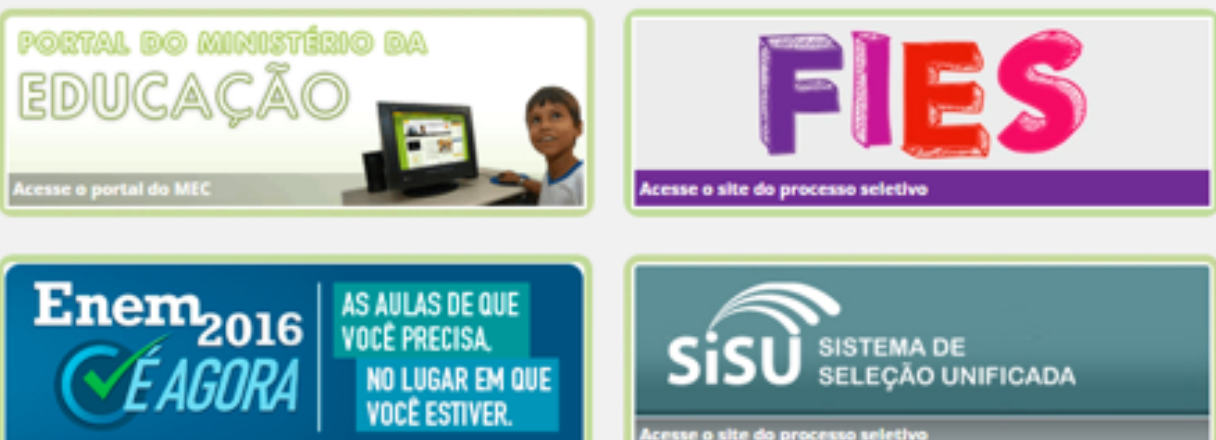

Fonte: <http://www.mec.gov.br/>. Acesso em: 07 nov. 2016.

Nessa instância da apresentação do site, o usuário tem a alternativa de navegar pelo domínio do ministério através de quatro opções na trajetória dessa prática, segundo seus interesses: Ele pode optar por entrar no portal do MEC, que seria o link que redireciona o usuário ao portal oficial ou, ainda, se o seu interesse for mais específico, buscar diretamente informações relacionadas ao FIES, PROUNE ou ENEM, canais diretamente ligados aos alunos que buscam informações sobre as bolsas de estudos e programas oferecidos pelo governo.

Podemos considerar que essa seria a primeira cena predicativa na qual interagem os sujeitos dessa prática comunicativa em uma ação de escolha. O enunciador apresenta títulos informativos através da linguagem sincrética (superposições de cores, formas e linguagens) como portas de entrada para outras páginas da própria instituição. Uma estratégia de distribuição topológica que deixa transparecer que o enunciador (MEC) procura facilitar a busca pelo conteúdo desejado. 
Observa-se que o portal utiliza seus títulos e ilustrações de forma direta e objetiva, com ilustrações que reforçam o conteúdo apresentado e proporcionam ao enunciatário a busca por informações específicas, otimizando o seu tempo.

Entre essas opções de navegação, a primeira, do lado esquerdo da tela, intitulada Portal do Ministério da Educação, é a que nos leva, especificamente, ao seu site. Dessa forma, chegaremos a sua principal página ${ }^{6}$, ilustrada em (2) e (3).

Figura 2 - Print da página principal do Portal do MEC
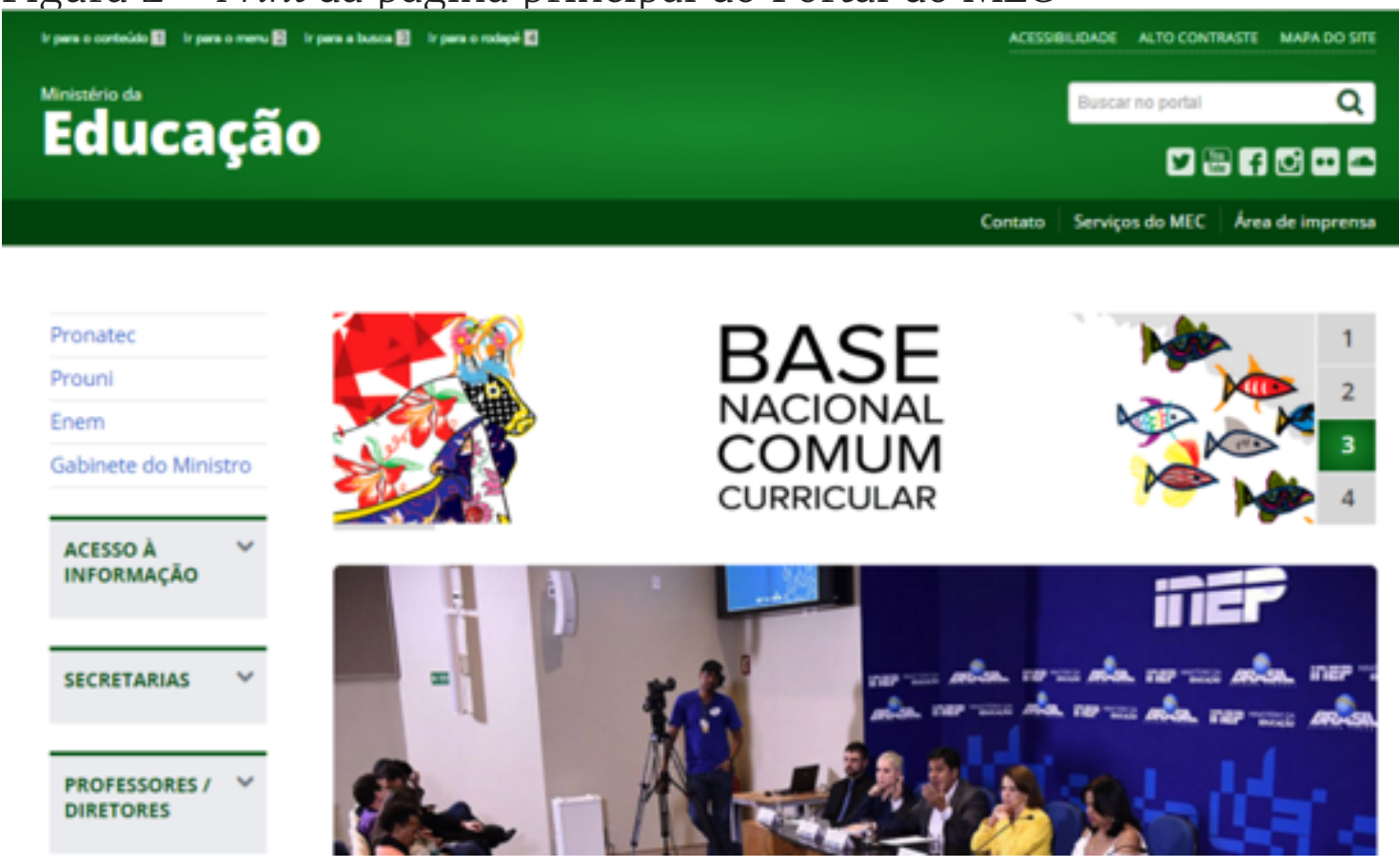

Fonte: <http://portal.mec.gov.br/index.php>. Acesso em: 07 nov. 2016.

\footnotetext{
${ }^{6}$ As figuras utilizadas são prints de tela de acordo com a rolagem da barra lateral do notebook utilizado, pois, como sabemos, o formato de uma página na Internet é um sistema monobloco que pode ser acessado completamente de acordo com essa rolagem da tela.
} 
V. $8(2)$

$13-38$

mai/ago 2018

Figura 3 - Print da página principal do Portal do MEC

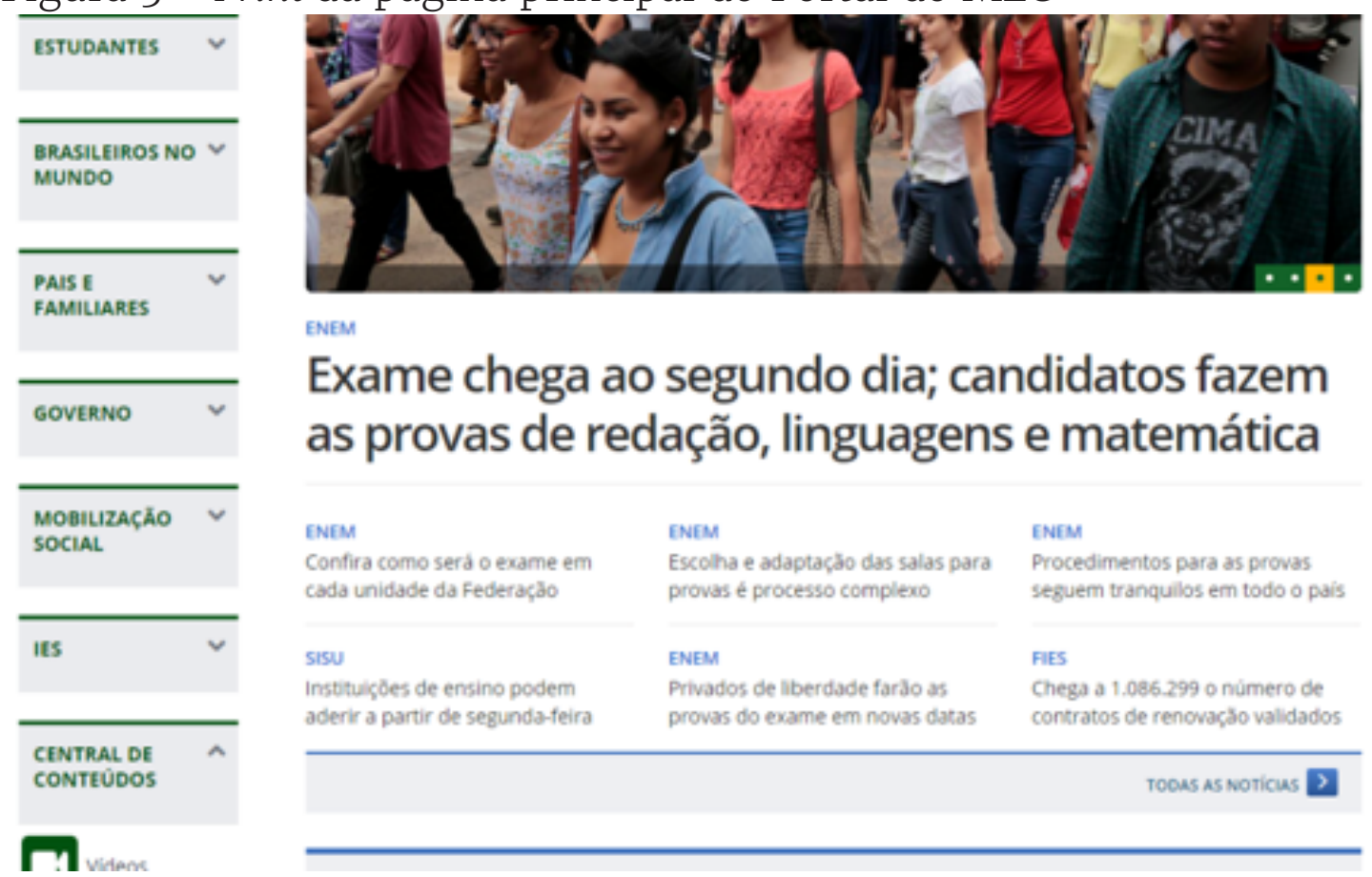

Fonte: <http://portal.mec.gov.br/index.php>. Acesso em: 07 nov. 2016.

Na organização topológica7 do site, temos um cabeçalho contendo o nome da instituição, um campo de busca, algumas informações sobre formatação da tela e caminhos que podem levar o internauta para outros espaços do MEC na Internet, como por exemplo, suas páginas nas redes sociais.

O MEC, em sua organização cromática, é representado em seu portal pela cor verde. Ela aparece na moldura do site e nos títulos afixados, é a cor de destaque, que predomina. Ao remeter-se a uma cor da bandeira nacional, o MEC institucionaliza-se enquanto ministério e confere ao ambiente um valor de oficial, de autoridade e, portanto, de efeito de sentido de verdade. Temos, aqui, instaurado um contrato de veridicção que modaliza o seu destinatário a crer naquele ambiente através do uso de um signo visual marcado pela cor verde, a cor institucional. Dessa forma, o MEC garante o seu papel de destinador social e determina um "efeito de verdade inquestionável" (PORTELA, 2008b).

Na coluna do lado esquerdo, encontraremos portas de entrada que facilitam a navegação por locais específicos, por exemplo, secretarias, governo, professores e estudantes, diretores, entre outros, como ilustra a figura 4 .

7 Estudo sobre a colocação ou disposição das palarvras, frases, textos ou seções em determinados ambientes. 
Figura 4 - Menu lateral do Portal do MEC

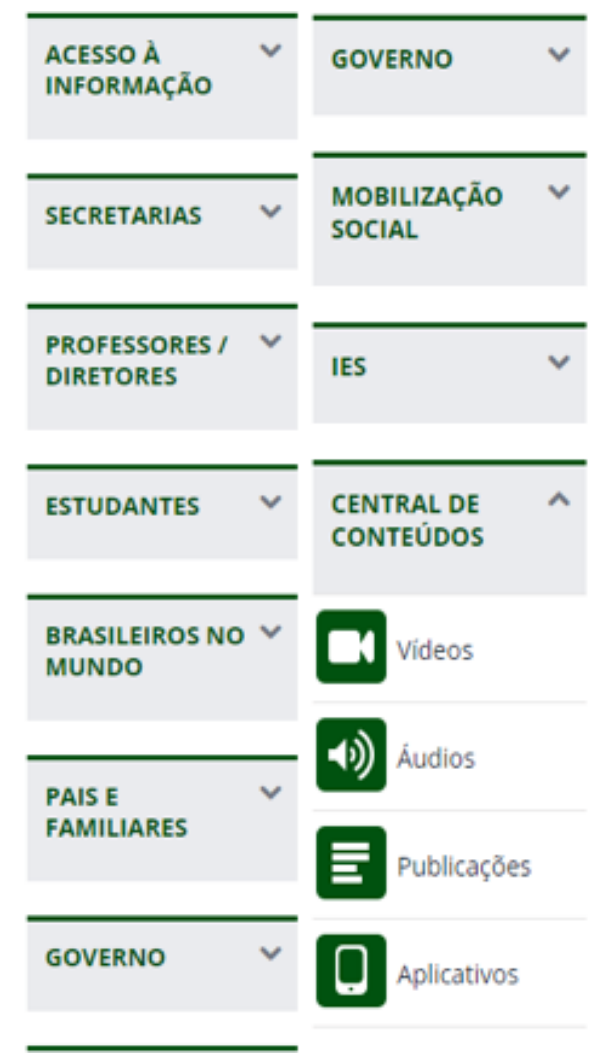

Fonte: http://portal.mec.gov.br/ index.php. Acesso em: 07 nov. 2016.

Observando os títulos desses nichos, podemos identificar alguns dos enunciatários do Ministério nesse ambiente, ou seja, com quem o MEC tem um interesse específico em se comunicar, os chamados "passageiros escolhidos", de acordo com os conceitos de Landowski (2012, p. 78). São eles: professores e diretores, estudantes, brasileiros no mundo (interessados em intercâmbios), pais e familiares. Instaurase assim, de maneira mais clara, o "outro" com quem o Ministério procura manter a sua relação nesse espaço.

Para que essa interação se conclua de forma satisfatória, esse "outro", sujeito coletivo e ao mesmo tempo virtual 9 , precisa estar modalizado a um querer ou um dever-fazer e a um poder-fazer aquela ação de busca (navegação) pelo portal, ao passo que seu enunciador, o MEC, proporciona a facilitação, a acessibilidade, a organização em

\footnotetext{
${ }^{8}$ Passageiros (viajantes) que transitam pelo espaço a fim de reconhecerem-se ali. (LANDOWSKI, 2012, p. 78)

9 Segundo Barros (2001, p.53), o sujeito definido pelo dever ou pelo querer-fazer é chamado sujeito virtual e, o sujeito definido pelo saber e/ou poder-fazer, é chamado sujeito atualizado.
} 
v. $8(2)$

$13-38$

mai/ago 2018

seu espaço, oferecendo condições para que esse sujeito se atualize, ou seja, para que o seu enunciatário passe a saber e a poder-fazer essa ação dentro do ambiente digital.

Podemos observar que o próprio objeto de inscrição se torna um mecanismo de modalização entre os sujeitos da enunciação. Através da organização topológica e cromática dos textos-enunciados pelo MEC em seu portal, podemos encontrar marcas dessa enunciação pressuposta que nos permitem reconstituir o ato enunciativo, como, por exemplo, o posicionamento das seções que fazem com que os seus "passageiros escolhidos" se encontrem no espaço e consigam transitar por ele sem dificuldade, o que pressupõe que houve uma preocupação no momento da enunciação para que houvesse acessibilidade na comunicação.

No momento dessa interação, uma nova cena predicativa é constituída na qual a interação somente ocorrerá no tempo e espaço programados a partir das escolhas de navegação. O enunciatário, ao clicar no nicho com o título de seu interesse, mobiliza um percurso que constituirá uma cena predicativa, ou seja, enunciador e enunciatário darão seguimento a uma situação semiótica, modalizados através de seus papéis actanciais de sujeitos do nível narrativo.

O percurso por esses espaços é descontínuo, pois se trata de um ambiente aberto, transitável e o internauta pode navegar por onde tem mais interesse ou necessidade. Mas, mesmo assim, podemos pressupor, de acordo com o gênero documento (que são artigos, leis, diretrizes, estatutos etc), que é o mais utilizado na abertura dos links desses nichos, que o enunciatário do MEC, nesse ambiente, é modalizado por um deverfazer, pois, o interesse pelo acesso a algum documento digitalizado, pressupõe que esse enunciatário deva fazer alguma pesquisa ou mesmo tirar alguma dúvida, seguindo um protocolo de leitura proposto pelo enunciador de acordo com os regimes sintagmáticos (Fontanille, 2008) da prática da visita.

Centralizado, ou seja, em maior destaque, encontra-se uma TAG sempre em movimento, mudando seu conteúdo após alguns segundos. O ministério evidencia quatro temas que julga relevantes àquele momento em que foi exposto como forma de direcionamento para outros links.

Em seguida, apresenta um banner que contém sempre algumas notícias relevantes àquele período em que está à mostra, como, por exemplo, propostas e decisões governamentais destacadas para o conhecimento de todos. Essas notícias não têm um tempo determinado 
de permanência, elas são alteradas de acordo com novos acontecimentos no âmbito educacional, portanto, um banner pode durar um dia, ou até estar por semanas em destaque, como verificamos em nossas observações durante a construção deste trabalho.

O mais importante dessa estratégia topológica de usar o banner centralizado e em movimento é a captura da atenção do usuário que, na eventual visita, modalizado a cumprir um programa de leitura de acordo com sua necessidade, desvia a sua atenção para uma notícia do ministério, marcando um percurso de descontinuidade. Essa atração se dá também pelo sincretismo empregado a esse texto topologicamente acessível, no qual imagens e palavras (textos) convocam a atenção do sujeito-leitor que passa a conduzir um outro ritmo de leitura, possivelmente, mais tônico e intenso.

Abaixo desse banner, encontram-se outros links de notícias, seções de vídeos em destaques, podcasts, uma seção de notas oficiais e, para finalizar, informações sobre os órgãos vinculados ao MEC, como mostram as figuras (5) e (6) a seguir.

Figura 5 - Seção de vídeos e áudios

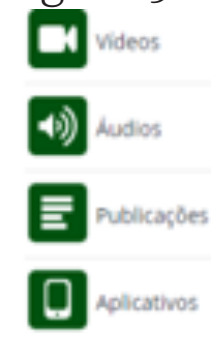

Videos e áudios em destaque
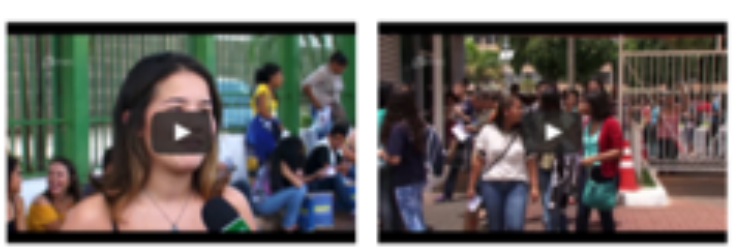

Insthuichos de educaclo superior podem aderir ao Sistema de Seleça feira, 7. Prazo vai ate dia 23

Primeiro dia do Enem reùne estudantes de todo o pais s.3as.sat eitudantes dewem faser a aplicadas as provas de cdecias humanas e dansturesa com 4 heras e 30 minutss de duraslo.

Para Mendonça Filho, Enem foi um sucesso

o ministro da tducaço apresentou um balango do fnem neibe fim de semana e walcu o processo como um sucesia. As provas foram aplcadas para sit mindes de alunos en todo pais.

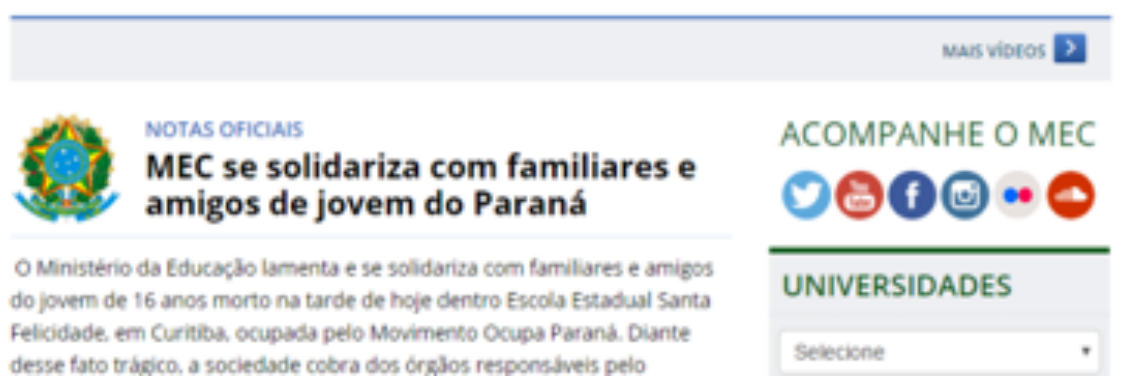

Fonte: <http://portal.mec.gov.br/index.php>. Acesso em: o7 nov. 2016. 
V. $8(2)$

$13-38$ mai/ago 2018

Figura 6 - Outros links e informações sobre órgãos vinculados ao MEC
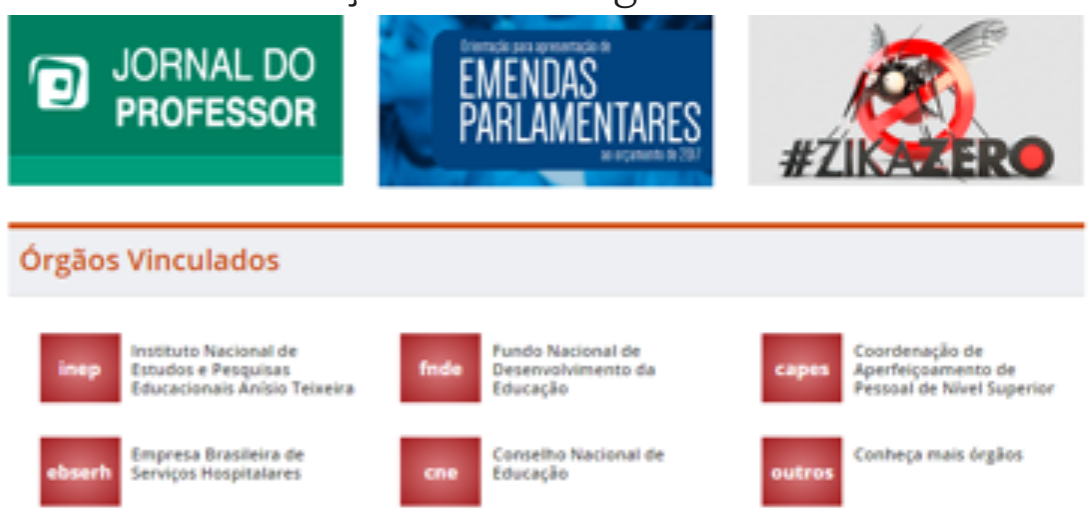

A voltar para o topo

Assuntos

Profenseres $/$ Diretaren

Eveudartes

Pus e farthares

Covemo
Serviços

costento

Servigen do Mic

Area de imprensa
Redes Sociais

Twiater

Youtube

Facebeck

Imearam
RSS

oque

axine

Sobre o site

Fonte: <http://portal.mec.gov.br/index.php>. Acesso em: 07 nov. 2016.

O site é bissensorial, utiliza-se dos dois sentidos possíveis até então pela Internet, a visão e audição, portanto, estamos transitando por um espaço de heterogeneidade multimodal, ou seja, de várias "regras de constituição" que levam ao sincretismo, conforme nos esclarece Fontanille (2005, p. 78).

Observamos logo no canto superior, à direita (ver figura 7, a seguir), na moldura do site, a lupa, que nos remete à ideia de pesquisa, busca, procura. Na figura 8, temos exemplos do uso de figuras visuais que simulam objetos da vida real: uma câmera para representar o ícone de vídeos, um megafone representando os áudios, uma folha para as publicações e um celular para os aplicativos. Todos esses pictogramas traduzem uma experiência da vida fora do espaço digital e facilitam o desempenho do internauta dentro do ciberespaço. 
Figura 7 - Janela de busca

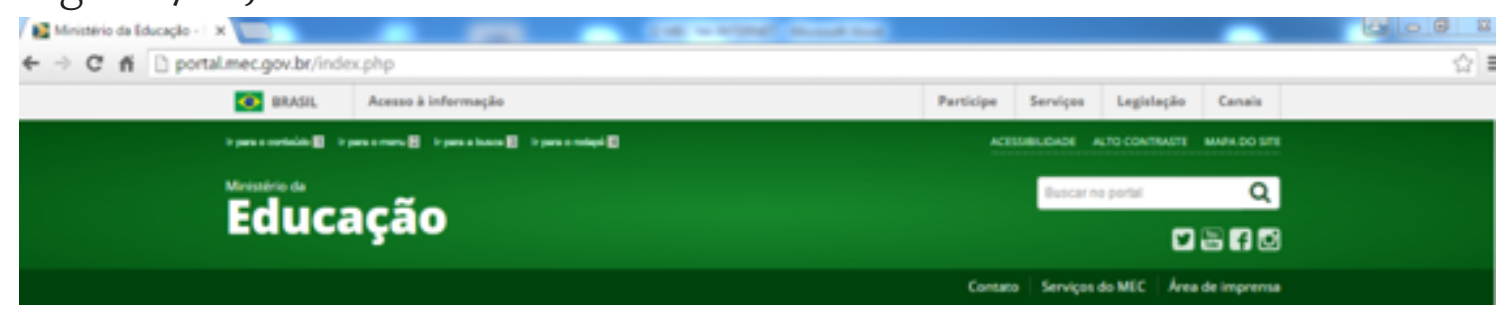

Fonte: <http://portal.mec.gov.br/index.php>. Acesso em: 07 nov. 2016.

Figura 8 - Ícones para seções do site

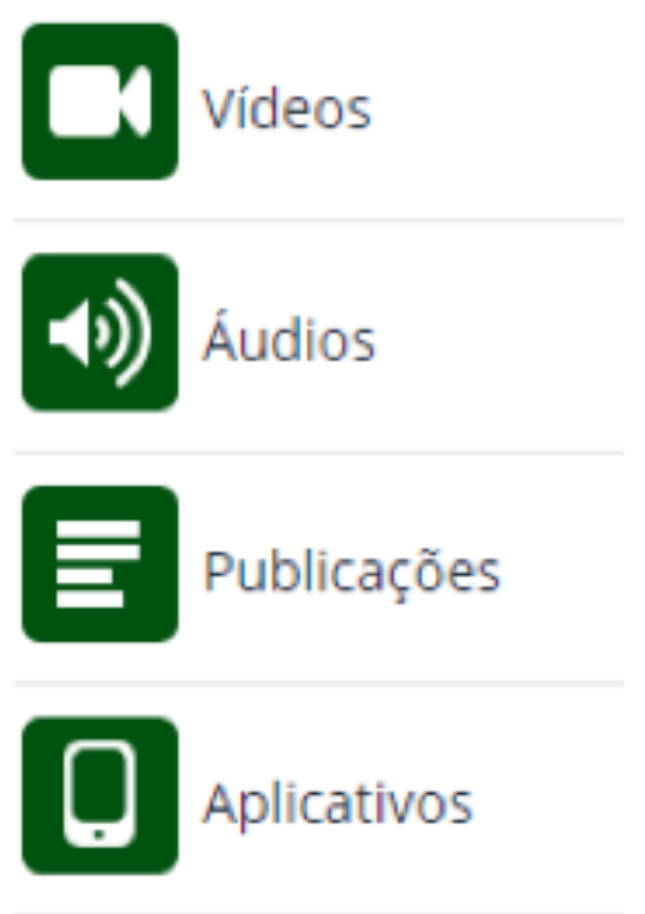

Fonte: <http://portal.mec.gov.br/index.php>. Acesso em: 07 nov. 2016.

Como esclarece Fontanille (2005, p. 101), "o ícone apresenta um certo grau de semelhança com aquilo que evoca", revelando a própria homologação dos planos de conteúdo e expressão, portanto, esses recursos icônicos nos remetem à ideia de acessibilidade, são facilitadores da navegação pelo Portal.

As divisões das seções, os títulos, os ícones utilizados, as ilustrações, o ritmo da rodagem das mensagens favorecem o acesso e padronizam a sintaxe do espaço com muitos outros sites ou portais brasileiros que se utilizam da mesma roupagem, assim como o fato de integrarem a linguagem verbal com a visual para facilitar a navegação e a interação. 
V. $8(2)$

13-38

mai/ago 2018

O quadro a seguir esboça em esquema estrutural a primeira página do Portal.

Quadro 1 - Esquema da primeira página do Portal do MEC

\section{1-Cabeçalho}

(nome da instituição, campo de pesquisa, informações adicionais) Linguagem verbal e não- verbal (cores e ícones)

2-Coluna
vertical
Nichos com
temáticas
variadas

Enunciatários

Gênero:

Documento e informativo

Linguagem verbal e nãoverbal (cores)

Gênero informativo

Linguagem verbal e não-verbal (imagens)

$$
\text { 5-Banner - Gênero jornalístico (notícias) }
$$

Linguagem verbal e não-verbal (imagens)

6- : Vídeos e áudios em destaque

Gênero jornalístico (notícias)

Linguagem verbal (falada e escrita) e não-verbal (imagens)

$$
\text { 7- : Notas oficiais }
$$

Gênero: jornalístico (decisões governamentais)

Linguagem verbal e não-verbal (imagens)

$$
\text { 8-: Órgãos vinculados }
$$

$$
\text { Gênero: informativo }
$$

3-Relação de links

Gênero jornalístico e documento

Linguagem verbal e não verbal (ícones)
Linguagem verbal e não-verbal (cores)

$$
\text { 9- Moldura final }
$$

Informações sobre o site

Gênero: informativo

Linguagem verbal e não-verbal (cores e imagens)

Fonte: elaborado pelas autoras. 
Como podemos observar, o sincretismo está presente em todas as seções. O efeito de sentido que essa articulação de elementos causa é de uma interação entre o enunciador e o enunciatário marcada pela descontração, pela dinamicidade e pela modernidade, ou seja, pela ruptura de um modelo antigo no qual predominavam os textos verbais impressos. Nesse espaço, o MEC se posiciona em uma versão reconfigurada, dotada de recursos visuais e de novas práticas participativas o que, de certa forma, facilita a persuasão do enunciador, pois esse novo suporte oferece ao enunciatário uma experiência mais dinâmica, menos cansativa e prática, já que antes, para acessar qualquer conteúdo oferecido pelo MEC era preciso encontrá-lo em sua forma material, como em livros, revistas, jornais, entre outros.

Quanto à distribuição topológica das seções, observamos também que a maioria delas está na ordem horizontal, na ordem do olhar, somente um campo é colocado na vertical, o dos nichos, portanto, a fluidez é um efeito de sentido interessante de se tratar nesse contexto. A leitura ocidental é feita linearmente, na horizontal, o nosso olhar representa uma horizontalidade do espaço, portanto, a organização do ambiente nesse sentido facilita a leitura e, ao mesmo tempo, garante a fluidez. Outra questão interessante é que, apesar da horizontalidade da maioria das seções, elas se colocam em blocos verticais, uma sobreposta a outra respeitando os limites do objeto-suporte em que se encontram. Uma página na Internet requer uma rodagem vertical para que todo o conteúdo possa ser visualizado em seu sistema monobloco.

Toda essa distribuição topológica é feita para facilitar a acessibilidade, a redação, o desenvolvimento, a manutenção, a arquitetura de informação e o desenho, sendo o objetivo principal qualificar o desenvolvimento do Portal, tornando-o acessível e simples para seus enunciatários na busca pelas informações.

O primeiro bloco a ser visualizado, ao abrirmos o portal, é o que contém mais elementos sincréticos, com imagens, entre figuras e fotografias. Esse recurso serve para direcionar o usuário para dentro desse espaço. São as seções da TAG e do banner que ganham maior notoriedade. Além dessa atratividade das imagens sincréticas, essas seções ganham movimento e mudam a cada sete segundos. Essa seria mais uma estratégia enunciativa para direcionar a atenção do usuário. Direcionar, nesse sentido, seria, através do objeto-suporte e com o agrupamento de várias linguagens, programar o conteúdo que se quer ou se deve transmitir, ou seja, o MEC impõe aos seus enunciatários o que 
V. 8 (2) $13-38$ mai/ago 2018

concebe como prioridade de divulgação, que podem ser resultados de ações ou estratégias governamentais, nesse caso, exposições positivas a respeito das medidas tomadas na educação do Brasil. Segundo Oliveira (2009), a expressão sincrética passa a ser uma escolha do enunciador para expressar o conteúdo desejado.

Na verdade, quanto mais explorarmos o plano da expressão e seus efeitos de sentido, mais próximos ficamos do plano de conteúdo, pois, ao tecermos todo esse mecanismo de apreensão através da plasticidade, descortinamos os porquês e as intenções de todo esse aparato visual. Como podemos abstrair das palavras de Floch (2009, p.151) "não há expressão senão em relação a um conteúdo, não há significante senão em relação a um significado".

\section{Abordagem genérica}

Seguiremos a análise para tentarmos personificar ainda mais esses sentidos, agora, com ênfase no banner central para que consigamos entender como a escolha do gênero nessa seção promove essa prática.

Figura 9 - Banner central do site

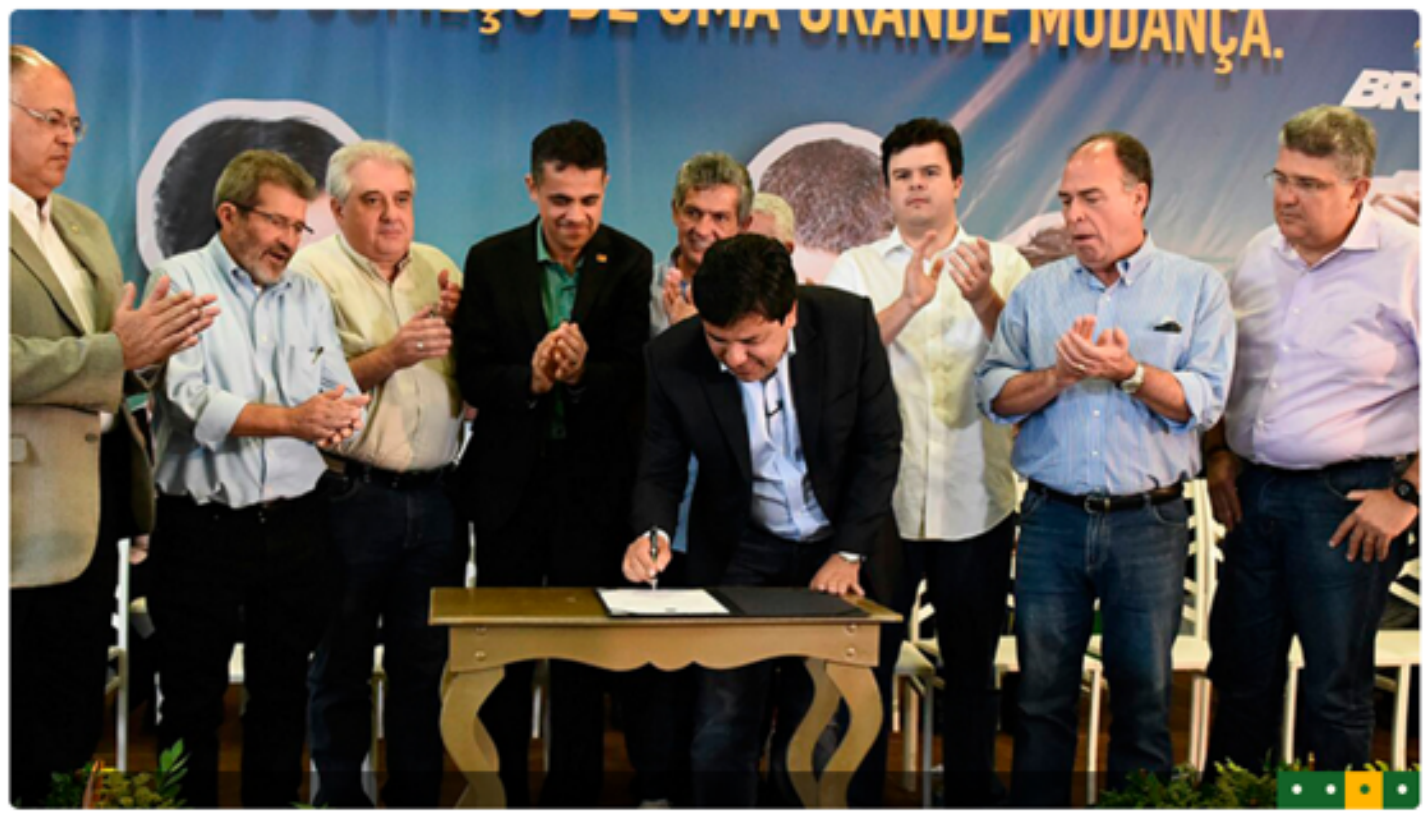

ENSINO SUPERIOR

\section{MEC autoriza instalação do primeiro campus da Univasf no Sertão Central de Pernambuco}

Fonte: <http://portal.mec.gov.br/index.php>. Acesso em: 25 ago. 2017. 
Foi utilizado o gênero jornalístico de cunho informativo. Há uma preocupação com a imagem que acompanha a manchete que, como averiguamos, são fotografias que complementam ilustrativamente o conteúdo verbal apresentado. Segundo Portela e Schwartzmann (2012):

O grande nome da teoria dos gêneros contemporânea é sem dúvida $\mathrm{M}$. Bakhtin, cuja reflexão a respeito da natureza social da enunciação produziu a noção de "gêneros do discurso" como "tipos relativamente estáveis de enunciados" que podem ser analisados pelos critérios "conteúdo temático", "estilo" e "construção composicional" (BAKHTIN, 2003, p. 261-262 apud PORTELA; SCWARTZMANN, 2012, p. 70).

Refletindo sobre a definição bakhtiniana de que o gênero constitui-se como um tipo relativamente estável de enunciado, podemos considerar que o MEC escolhe o jornalismo informativo para compor o principal espaço de sua página, a fim de estabelecer uma relação de credibilidade com seu enunciatário, pois, culturalmente, os jornais (sejam impressos ou televisivos) são considerados fontes idôneas de informações.

Além disso, há apenas uma ilustração e a manchete e, para se ter acesso à integra da notícia, o enunciatário deve acessar o link, o que pode ou não acontecer, pois muitas pessoas, pelo tempo escasso, pela falta de interesse ou ainda por se satisfazer apenas com a manchete, não acessará essa integralidade, o que pode ser uma estratégia do enunciador, pois pode deixar implícita na manchete alguma informação relevante, que complemente a manchete. Podemos, dessa forma, concluir que o gênero subscreve-se de forma diferente de acordo com o objeto-suporte de inscrição. Nesse caso, a cena prática de acesso ao link determina o que se lê e como se lê o texto.

Podemos elucidar que o MEC, em seu discurso, no momento da enunciação, procura utilizar-se da composição jornalística para dar congruência entre o que quer dizer e o como dizer, ou seja, a escolha tipológica do texto é coerente ao discurso que quer instaurar nesse ambiente de interação, como podemos observar pelas palavras de Portela e Schwartzmann (2012, p. 76):

A base da reflexão de Fontanille funda-se sobre dois conceitoschave: a coesão, que seria de ordem textual, e a coerência, de ordem discursiva, duas variáveis que são reguladas e regidas pela congruência. Essas seriam as três dimensões dessa forma de "negociação" (FONTANILLE, 1999, p. 18) que existe entre os tipos textuais e os tipos discursivos, resultando em um determinado gênero. 
V. $8(2)$

$13-38$

mai/ago 2018
Sobre a coesão, ou seja, a tipologia desse texto, podemos observar a construção da linguagem, como por exemplo: as construções frasais são simples e curtas, geralmente, na ordem direta (sujeito verbo - predicado). Dessa forma, essas cosntruções não exigem um esforço interpretativo da parte do enunciatário e definem bem o sujeito da ação, ou seja, quem é que está realizando as boas ações referidas. Também a utilização da linguagem é cotidiana, com palavras de utilização correntes, não há utilização de um léxico formal, rebuscado ou inacessível, o que também facilita a interpretação e o entendimento.

Essa notícia, no banner principal, é ilustrada por uma fotografia, um registro do momento em que foi assinada a autorização para a instalação do primeiro campus da Univasf pelo então Ministro da Educação Mendonça Filho. Atrás dele, outras pessoas aplaudem a ação desse momento. Podemos atribuir essa coesão entre a imagem e a linguagem verbal às considerações de Floch (2001) sobre a homologação do plano de conteúdo e o plano de expressão, que resulta na acepção de semissimbolismo, pois acreditamos que haja uma homologação entre conteúdo e expressão nessa imagem, a qual confere-se entre a imagem do Ministro assinando o documento e, ao mesmo tempo, sendo aplaudido por essa ação com a manchete apresentada abaixo "MEC autoriza instalação do primeiro campus da Univasf no Sertão Central de Pernambuco. Assim, elucida-nos Floch (2009):

As linguagens semi-simbólicas caracterizam-se não pela conformidade de elementos da expressão e do conteúdo isolados, mas pela conformidade de certas categorias desses dois planos. Citam-se geralmente como formas semissimbólicas significantes as formas prosódicas e certas formas de gestualidade. (FLOCH, 2009, p. 161)

No que diz respeito à modalização desse discurso inserido nesse objeto-suporte, a Internet, podemos refletir que o enunciatárioleitor do Portal do MEC, ao acessar sua página, modalizado a um dever ou querer fazer essa visita, entra em contato diretamente com essa manifestação sincrética instaurada no banner, que está localizado propositalmente em plano central, a fim de atrair o olhar para essa dimensão topológica. Dessa forma, seu enunciatário-leitor depara-se com as notícias veiculadas pelo enunciador. A partir desse contato visual, o enunciatário será modalizado a um querer saber aquela informação, aderindo-a de forma persuasiva. 


\section{Conclusão}

Ao descrevermos e analisarmos o espaço do Portal do Ministério da Educação, tivemos a oportunidade de refletir sobre a questão do gênero e do sincretismo empregados como mecanismos de apreensão da atenção e de manipulação geradas através das estratégias enunciativas mobilizadas no interior dessa prática.

Esperávamos encontrar, no espaço do Portal, um ambiente mais interativo e voltado ao diálogo com professores, diretores e alunos, ou seja, com os principais sujeitos ligados a esse órgão institucional. Também esperávamos encontrar matérias sobre estratégias de ensinoaprendizagem, trocas de conhecimentos, destaques de projetos educacionais, entre outros assuntos mais específicos à área. Porém, houve uma ruptura desse pensamento à medida que observávamos a manifestação das linguagens no ambiente.

O estudo da organização do suporte planar nos foi revelando, aos poucos, as estratégias enunciativas do enunciador até que conseguíssemos abstrair o semissimbolismo remanescente dessa semiose.

Os usuários do portal, sujeitos envolvidos nesse esquema narrativo hipertextual, entram na página e, involuntariamente, são atraídos pela estrutura jornalística que ali se impõe. O olhar é deslocado automaticamente para o espaço central, provocado por imagens, cores, movimentos e ritmos. E é, exatamente, nesse lugar, que se encontra a maior estratégia de manipulação por parte do destinador dessa "mensagem".

O conteúdo veiculado nesse espaço sincrético passa a ser de ordem político-educacional, servindo como uma vitrine para o enunciador, comunicador dessa cena prática, o MEC. Através desse espaço, articulam-se as notícias e informações que o ministério quer que seus enunciatários saibam, podendo, em contrapartida, não expor outras que, talvez, fossem importantes também para seus enunciatários.

Estudar o sincretismo nos possibilitou entender como as linguagens foram articuladas a fim de gerar uma totalidade e refletirmos sobre a interação que ela provoca no caso de um suporte como a Internet, que hoje, sistematicamente, utiliza-se desse recurso para apreensão do sensível, emergindo-se como modalizante.

O gênero jornalístico no espaço do Portal é usado para alcançar e promover os objetivos do Ministério. Nota-se que esse gênero, deslocado 
v. $8(2)$

$13-38$

mai/ago 2018 para o suporte Internet, é estruturalmente modificado, principalmente por razão dos arranjos estruturais envolvendo movimento, ritmo e acessos diferentes de uma composição autônoma que deriva de um modelo clássico-normativo de gênero. O fato de o teor da notícia estar comprometida ao envolvimento de uma nova cena predicativa, ou seja, de um novo percurso de leitura, que se dará através da ação de clicar no link, já muda completamente a sua morfologia enquanto texto jornalístico contido em um jornal impresso. Nesse ambiente, a manchete (chamada) e as imagens tendem a ser muito mais persuasivas que o próprio texto, como comprovamos ao analisá-las. Estruturas frasais simples, com os sujeitos da ação bem marcados e os verbos semanticamente escolhidos para interagir facilmente com os sujeitos da leitura, os interpretantes desse discurso, que são, segundo Fiorin (2008) autores implícitos no texto, não de carne e osso.

A interação proposta por um meio eletrônico pressupõe um certo tipo de reação intensificada, já que, em vários sites, blogs e redes sociais há abertura para que os leitores interajam mutuamente. Porém, no Portal do MEC, especificamente analisado, no espaço dessas notícias, não há como estabelecer esse canal. Sendo assim, podemos considerar o ambiente fechado, uma vez que contraria a ideia de um ambiente aberto, interativo, típico do ecossistema digital da Internet, pois a única interação é de forma reativa, aquela na qual o internauta compartilha aquela notícia para outro espaço, twitter, facebook etc.

A significação, portanto, nesse objeto de análise, produziu-se através da organização de um sistema cultural, disponibilizado pelos signos escolhidos, pelos textos manifestados, pelas possibilidades do objeto-suporte e pelas estratégias enunciativas e de manipulação que, relacionadas, construíram a prática comunicativa do MEC por esse espaço, possibilitando refletirmos sobre o seu comportamento ali insaturado.

Estudar a prática de comunicação do MEC pelo seu Portal nos permitiu enxergar a força persuasiva de um órgão social sob os cidadãos, os membros de um Estado que deveriam gozar de seus direitos, participando ativamente da vida política. A dimensão cultural que o comportamento de um ministério emerge é um passo a mais na prática analítica do semioticista. 


\section{Referências bibliográficas}

BARROS, D. L. de P. Teoria do Discurso: Fundamentos Semióticos. 3. ed. São Paulo: Humanitas/FFLCH/USP, 2001.

CÂMARA, N.S. Letramentos Transmídia. In: SANTAELA, L. Revisão crítica transmídia. 2018. (no prelo).

FIORIN, J. L. Semiótica e comunicação. In: DINIZ, M. L. V. P.; PORTELA, J. C. (Org). Semiótica e mídia: textos, práticas, estratégias. Bauru: UNESP/FAAC, 2008.

FIORIN, J. L. As astúcias da enunciação. 3. ed. São Paulo: Contexto, 2016.

FLOCH, J. M. Alguns conceitos fundamentais em semiótica geral. In: Documentos de Estudo do Centro de Pesquisas Sociossemióticas. São Paulo: CPS, 2001.

FLOCH, J. M. Semiótica plástica e linguagem publicitária: análise de um anúncio da campanha de lançamento do cigarro "News". trad. José Luiz Fiorin. In: OLIVEIRA, A. C. de.; TEIXEIRA, L. (Org.) Linguagens na Comunicação: desenvolvimentos de semiótica sincrética. São Paulo: Estação das Letras e Cores, 2009.

FONTANILLE, J. Significação e Visualidades: exercícios práticos; trad. Elizabeth B. Duarte e Maria Lília D. de Castro. Porto Alegre: Sulina, 2005.

FONTANILLE, J. Práticas semióticas: imanência e pertinência, eficiência e otimização. In: DINIZ, M. L. V. P.; PORTELA, J. C. (Org). Semiótica e mídia: textos, práticas, estratégias. Bauru: UNESP/FAAC, 2008.

FONTANILLE, J. Sémiotique et littérature: Essais de méthode. Paris: PUF, 1999.

GREIMAS A. J.; FONTANILLE, J. O belo gesto. Trad. Edna Maria Fernandes dos Santos Nascimento. In: NASCIMENTO, E. M. F. dos S.; ABRIATA, V. L. R. (org). Formas de Vida: rotina e acontecimento. Ribeirão Preto: Coruja, 2014.

GREIMAS A. J.; COURTÉS, J. Dicionário de semiótica. 2. ed., 3ª reimpressão. São Paulo: Contexto, 2016.

HJELMSLEV, L. Prolegômenos a uma teoria da linguagem. São Paulo: Perspectiva, 1975.

LANDOWSKI, E. Presenças do outro. São Paulo: Perspectiva, 2012.

OLIVEIRA, A. C. A plástica sensível da expressão sincrética e enunciação global. In: OLIVEIRA, A. C. de.; TEIXEIRA, L. (Org.) Linguagens na Comunicação: desenvolvimentos de semiótica sincrética. São Paulo: Estação das Letras e Cores, 2009.

PORTELA, J. C. Semiótica midiática e níveis de pertinência. In: DINIZ, M. L. V. P.; PORTELA, J. C. (Org). Semiótica e mídia: textos, práticas, estratégias. Bauru: UNESP/FAAC, 2008s. 
V. $8(2)$

$13-38$

mai/ago 2018

PORTELA, J. C. Práticas didáticas: um estudo sobre os manuais brasileiros de semiótica. 2008. Tese (Doutorado em Letras: Linguística e Língua Portuguesa) - Faculdade de Ciências e Letras de Araraquara, Universidade Estadual Paulista, Araraquara, 2008b.

PORTELA, J. C; SCHWARTZMANN, M. N. A noção de gênero em semiótica. In: PORTELA, J. C.; BEIVIDAS, W.; LOPES, I. C.; SCHWARTZMANN, M. N. (Org.). Semiótica: Identidades e diálogos. São Paulo: Cultura Acadêmica, 2012. p. 69-98.

TEIXEIRA, L. Para uma metodologia dos textos verbos visuais. In OLIVEIRA, A. C. de.; TEIXEIRA, L. (Org.) Linguagens na Comunicação: desenvolvimentos de semiótica sincrética. São Paulo: Estação das Letras e Cores, 2009.

TEIXEIRA, L. Museus on-line: novas práticas de visita. In: TEIXEIRA, L.; CARMO JR., J. R. do (Org.). Linguagens na cibercultura. São Paulo: Estação das Letras e Cores, 2013.

TEIXEIRA, L. Percursos de visita em sites da Internet. Revista Casa: Cadernos de Semiótica Aplicada. Araraquara, v.13, n.2, 2015, p. 33-55. 